Olson, J. A. \& Anfinsen, C. B. (1953). J. biol. Chem. (in the Press).

Parks, G. S. \& Huffman, H. M. (1932). The Free Energies of Some Organic Compounds. New York: Reinhold.

Parks, G. S., Huffman, H. M. \& Barmore, M. (1933). J. Amer. chem. Soc. 55, 2733.

Parks, G. S., West, T. J., Naylor, B. F., Fujii, P. S. \& McClaine, L. A. (1946). J. Amer. chem. Soc. 68, 2524.

Pinching, G. D. \& Bates, R. G. (1950). J. Res. nat. Bur. Stand. 45, 322, 444.

Racker, E. (1950). J. biol. Chem. 184, 313.

Robinson, R. A., Smith, P. K. \& Smith, E. R. B. (1942). Trans. Faraday Soc. 38, 63.

Rossini, F. D. (1932). J. Res. nat. Bur. Stand. 8, 119.

Rossini, F. D. (1934). J. Res. nat. Bur. Stand. 13, 189.

Rossini, F. D., Wagman, D. D., Evans, W. H., Levine, S. \& Jaffe, I. (1952). Selected Values of Chemical Thermodynamic Properties. Nat. Bur. Stand. Circular no. 500.

Saxton, B. \& Darken, L. S. (1940). J. Amer. chem. Soc. 62 , 846.

Scatchard, G., Hamer, W. J. \& Wood, S. E. (1938). J. Amer. chem. Soc. 60, 3061.
Schmidt, C. L. A. (1938). Chemistry of the Amino Acids and Proteins. Springfield: Charles C. Thomas.

Slein, M. W. (1950). J. biol. Chem. 186, 753.

Smith, E. R. B. \& Smith, P. K. (1942). J. biol. Chem. 146, 187.

Smith, P. K. \& Smith, E. R. B. (1937). J. biol. Chem. 121, 607.

Smith, E. R. B. \& Robinson, R. A. (1942). Trans. Faraday Soc. 38, 70.

Stadtman, E. R. (1952). J. biol. Chem. 196, 535.

Stedman, D. F. (1928). Trans. Faraday Soc. 24, 289.

Stern, J. R., Shapiro, B., Stadtman, E. R. \& Ochoa, S. (1951). J. biol. Chem. 193, 703.

Stiehler, R. D. \& Huffman, H. M. (1935). J. Amer. chem. Soc. 57, 1734, 1741.

Sturtevant, J. M. (1937). J. Amer. chem. Soc. 59, 1528.

Warburg, O. \& Christian, W. (1942). Biochem. Z. 310, 384.

Wolfrom, M. L. \& Lewis, W. L. (1928). J. Amer. chem. Soc. 50, 837.

Woods, D. D. (1936). Biochem. J. 30, 515.

Woolf, B. (1929). Biochem. J. 23, 472.

Wurmser, R. (1951). Ann. Rev. Biochem. 20, 1.

\title{
Oxidative Phosphorylation
}

\author{
BY H. A. KREBS, A. RUFFO, MONICA JOHNSON, L. V. EGGLESTON AND R. HEMS \\ Medical Research Council Unit for Research in Cell Metabolism, Department of Biochemistry, \\ University of Sheffield
}

(Received 14 July 1952)

It is known from the work of Engelhardt (1930, 1932), Runnström, Lennerstrand \& Borei (1934), Kalckar (1939, 1941, 1944), Belitzer \& Tsibakowa (1939), Cori and his associates (Colowick, Welch \& Cori, 1940; Colowick, Kalckar \& Cori, 1941) and Ochoa $(1941,1943,1947)$ that the free energy of oxidative processes can be used for the synthesis of organic phosphates, including those containing energy-rich bonds, namely, adenosinetriphosphate (ATP) or creatine phosphate. The quantitative aspects of the 'oxidative phosphorylation' i.e. the value of the ratio

$$
\frac{\text { equivalents of organic phosphate formed }}{\text { atoms of oxygen consumed }}
$$

has been studied by Ochoa $(1941,1943)$ and more recently by Hunter \& Hixon (1949a, b), Lehninger \& Smith (1949), Green, Atchley, Nordmann \& Teply (1949), Pardee \& Potter (1949), Slater (1950), Judah \& Williams-Ashman (1951) and others. The values obtained for the above ratio, henceforth in this paper called 'phosphorylation quotient', depend on experimental conditions. Of special interest are the maximum values that can be obtained. The highest quotients found so far approach the value of 4 (Barkulis \& Lehninger, $1951 a$; Judah, 1951). These valúes were usually obtained with tissue preparations which contained, apart from the oxidizing enzymes, ATP, hexo'kinase, inorganic phosphate and fluoride, and under these conditions most of the inorganic phosphate utilized appears as hexosephosphate. The presence of fluoride is required to prevent dephosphorylation of organic phosphate. The phosphate uptake values measured by this procedure have to be regarded as minimum values as dephosphorylation may not be completely abolished.

The present paper is concerned with measurements of the phosphorylation quotient by a procedure employing ${ }^{32} \mathrm{P}$ which has the advantage of being independent of the action of dephosphorylating enzymes. The use of ${ }^{32} \mathrm{P}$ as a tracer, combined with newer methods of separating the phosphorylated compounds by paper chromatography, makes it possible to measure directly the rate of synthesis of ATP even when no changes in the concentrations of ATP or of inorganic phosphate occur. It is therefore unnecessary to add fluoride or to apply corrections. 


\section{EXPERIMENTAL}

A respiring tissue preparation, reinforced with oxidizable substrates, ATP and ${ }^{\text {s2P }}$ in the form of inorganic orthophosphate (hereafter referred to as ${ }^{82} \mathrm{PO}_{4}$ ) is shaken in the presence of $\mathrm{O}_{2}$, the conditions being such as to keep the rate of respiration and the concentration of ATP and inorganic phosphate approximately constant. The rate of oxygen absorption is measured manometrically and the rate of formation of energy-rich phosphate bonds is calculated from the rate at which ${ }^{32} \mathrm{PO}_{4}$ is incorporated into the ATP molecule. The procedure requires specific activity determinations of the phosphate fractions in the tissue preparations, which in turn involve separation and quantitative determination of the various phosphates. Hanes \& Isherwood (1949) have supplied the chromatographic methods required for these separations.

It is already qualitatively known (Hummel \& Lindberg, 1949) that ATP exchanges phosphate groups with inorganic phosphate very rapidly. In liver homogenates containing about $10 \%$ (fresh weight) tissue and $5 \times 10^{-8} \mathrm{M}$ labile ATP phosphate the turnover rate of ATP (i.e. the time required to exchange a quantity of phosphate equal to the labile phosphate of ATP) is of the order of minutes at body temperature. This is too rapid for precise measurements. Experiments must therefore be carried out with dilute tissue suspensions ( $3 \%$ ) at a low temperature.

Measurement of turnover rate of ATP. It is assumed that two substances, $M$ and $N$, combine reversibly to form $M N$.

$$
M+N \rightleftharpoons M N,
$$

further, that a steady state is maintained so that the concentrations of the reactants remain constant and that the three reactants do not take part in other processes. No assumption is required about the mechanism maintaining the steady state. It is also irrelevant whether the 'reversible' reaction is in thermodynamic equilibrium or whether it is (as in the case here considered) a cyclic system in which the forward and backward reactions involve different mechanisms and different intermediate stages. If an isotopic form of $M$ (or $N$ ) is introduced and the rate of its disappearance or of its incorporation into $M N$ is measured, the rates of the forward and backward reactions of the system can be calculated; the problem, as Sheppard (1948) has pointed out, is identical with that of calculating the exchange of inorganic ions between tissue and surrounding mediums. The following formula of Krebs, Eggleston \& Terner (1951) is applicable:

$$
v=\frac{a b}{t(a+b)} \ln \frac{b x_{o}}{x(a+b)-a x_{o}},
$$

where $v=$ quantity of $N$ converted into, and formed from $M N$, per unit time; $a=$ quantity of $N ; b=$ quantity of $M N$; $x_{0}, x=$ relative quantity (specific activity) of isotope form of $N$ at $t_{o}, t$.

In applying this equation to the phosphorylation of ATP it has to be borne in mind that two phosphate groups of ATP may be readily interconvertible with inorganic phosphate. The position is therefore described by the scheme

$$
M+2 N \rightleftharpoons M N N,
$$

where $M$ represents adenosinemonophosphate (AMP), $N$ inorganic phosphate and $M N N$ adenosinetriphosphate. At least two stages are involved in the formation of $M N N$, one
$N$ being added or lost at each step. The work on myokinase (Kalckar, 1943) suggests that the following two reactions are involved ( $\mathrm{ADP}=$ adenosinediphosphate):

$$
\left.\begin{array}{l}
\text { ADP + phosphate } \rightleftharpoons \text { ATP }, \\
\text { AMP + ATP } \rightleftharpoons 2 \mathrm{ADP} .
\end{array}\right\}
$$

But, whatever the mechanism, the mathematical analysis (see Appendix) shows that formula (1) is also applicable to the reactions (2).

In using the formula (1) for the system (2), $a$ represents the quantity of inorganic phosphate and $b$ the quantity of labile ATP phosphorus. If $a$ is expressed in $\mu$ moles, $b$ has to be given in $\mu$ moles of labile ATP phosphorus, i.e. two-thirds of the total ATP phosphorus.

Experimental arrangements. To avoid complications from permeability barriers and slow diffusion, tissue suspensions (homogenates) were used. As already mentioned, the rates of $\mathrm{O}_{8}$ uptake and of oxidative phosphorylation in liver, heart or kidney suspensions are very rapid at $40^{\circ}$; even after 30-fold dilution of the tissue, added ATP was found to come into equilibrium with ${ }^{32} \mathrm{PO}_{4}$ within a few minutes, a rate at which no exact,measurements of pairs of values for $x$ and $t$ can be made. Since dilution beyond 30 -fold is liable to cause loss of enzyme activity, the reaction rate was reduced by lowering the temperature to $20^{\circ}$.

Special experimental arrangements are required so that the two premises hold true on which the theroretical treatment of the experimental finding rests, namely (1) that adenosine polyphosphates and inorganic phosphate are the only phosphorus compounds metabolized in the system; (2) that the concentrations of both ATP and inorganic phosphate remain constant. Both assumptions can never be rigidly correct but, by suitable choice of experimental conditions, the deviations from the premises can be made so small that they may be neglected.

Dilution of the tissue reduces the concentration of endogenous phosphates, and if the concentrations of added ATP and inorganic phosphate are relatively high $\left(0.5 \times 10^{-2} \mathrm{M}\right)$ the concentrations of all other phosphates which react metabolically are small. Moreover, the reactions between ATP and inorganic phosphate are relatively rapid in comparison with the reactions of other phosphates (e.g. the synthesis of nucleic acids or the phosphorylation of glucose through the hexokinase reaction) and side reactions are therefore in any case of negligible proportions (a few \% in $15 \mathrm{~min}$.). Their precise extent is measured in every experiment by the determination of the ${ }^{32} \mathrm{PO}_{4}$ in compounds other than ATP and inorganic phosphate.

The validity of assumption (2) is directly checked for each experiment by the quantitative determination of ATP and of inorganic phosphate in the system.

Special chemicals. Three different preparations of ATP were used. The first, used in about four-fifths of all experiments, was a barium salt prepared from rabbit muscle according to the directions of LePage (1949); the second was a commercial barium salt supplied by Boots Pure Drug Co. Ltd. and purified by dissolving in $0.2 \mathrm{~N}-\mathrm{HNO}_{3}$ and reprecipitation with $\mathrm{Hg}$ and $\mathrm{Ba}$ as described by LePage; the third was a preparation of the free acid kindly given by Roche Products Ltd. To convert the barium salts into the sodium salts, $85.5 \mathrm{mg}$. were dissolved in $0.8 \mathrm{ml} . \mathrm{N}-\mathrm{HCl}$ and water was added to $4 \cdot 2 \mathrm{ml}$. The $\mathrm{Ba}$ was precipitated by the calculated amount of $\mathrm{Na}_{2} \mathrm{SO}_{4}(0.4 \mathrm{ml} .0 .5 \mathrm{M})$, the precipitate was centrifuged off and the supernatant was neutralized, with about $0.4 \mathrm{ml} .2 \mathrm{~N}-\mathrm{NaOH}$. All operations were carried 


\section{Table 1. Composition of samples of ATP}

Percentage distribution of total phosphate

$\begin{array}{lccccc}\text { ATP } & \text { ADP } & \text { AMP } & \overbrace{\begin{array}{c}\text { Ortho- } \\ \text { phosphate }\end{array}}^{\text {Inorganic }} & \begin{array}{c}\text { Pyro- } \\ \text { phosphate }\end{array} & \begin{array}{c}\text { Other } \\ \text { phosphates }\end{array} \\ 68.8 & 21 \cdot 8 & 3.7 & 0 & 0 & 5 \cdot 7 \\ 86.0 & 11.0 & 0 & 3 \cdot 0 & 0 & 0\end{array}$

Free acid, Roche Products Ltd.

Barium salt prepared according to LePage (1949)

out at $0^{\circ}$. The concentration of ATP in the solution was about $0.016 \mathrm{M}$, i.e. $80 \%$ of the expected, owing to the loss by adsorption on to the precipitate (Bailey, 1949).

The concentration and purity of the ATP solution was determined by paper chromatography, by the method of Eggleston \& Hems (1952) and by phosphate determination in the solutions. Representative results are shown in Table 1. None of the preparations tested was $100 \%$ ATP. The preparation used in most experiments contained $86 \%$ ATP and $11 \%$ ADP.

Carrier-free $\mathrm{KH}_{2}{ }^{32} \mathrm{PO}_{4}$ prepared from ${ }^{32} \mathrm{~S}$ by bombardment with neutrons was obtained in aqueous solution from the Atomic Energy Research Establishment at Harwell. The sample, as received, was dissolved in about $0.5 \mathrm{ml}$. water and had an activity of about $1 \mathrm{mc}$. This solution was diluted with 'stock saline' to $10 \mathrm{ml}$. and a measured quantity of this dilution, giving about $1 \times 10^{6}$ counts $/ \mathrm{min}$. was used per vessel. When freshly prepared, $0 \cdot 1 \mathrm{ml}$. solution was required and this volume was measured with the Agla syringe of Burroughs Wellcome Ltd. For the sake of convenience and rapidity the tip of the syringe was fitted with a $15 \mathrm{~cm}$. length of flexible plastic Portex drainage tubing no. 4 (internal diam. $2 \mathrm{~mm}$.) provided with a tip of the same type of tubing no. 1 (1 mm. diam.). During the delivery of the radioactive solution into the manometer cups some slight pressure on the tubing, causing errors in the amounts delivered of 3-4\%, was unavoidable. The effects of such errors were eliminated in the final calculation by using the \% of total radioactivity present in the various phosphate fractions. The quantity of ${ }^{32} \mathrm{PO}_{4}$ added to the saline did not appreciably affect the total phosphate concentration. The radioactivity of the incubated tissue preparation was thus about $2-3 \mu \mathrm{c} . / \mathrm{ml}$. solution.

Tissue suspensions. In deciding on the composition of the medium, the main consideration was to maintain respiration and to make the level of inorganic phosphate of the same order as that of labile ATP phosphates, as approximate equality of inorganic phosphate and ATP favour the accuracy of measurement. Tissue ( $3 \mathrm{~g}$.) from a freshly killed animal was ground with $60.7 \mathrm{ml}$. 'stock saline', made up of the medium III described by $\mathrm{Krebs}$ (1950) (omitting $\mathrm{CaCl}_{2}$, phosphate and organic compounds), $2 \cdot 8 \mathrm{ml} .0 \cdot 1$ M-sodium phosphate buffer, $\mathrm{pH} \mathrm{7.4}$, and $1 \cdot 0 \mathrm{ml} .0 \cdot 1 \mathrm{M}-\mathrm{MgCl}_{2}$. All saline media were ice-cooled, and grinding was carried out in an ice-cooled stainless-steel homogenizer similar to the glass apparatus recommended by Potter \& Elvehjem (1936). The final $\mathrm{pH}$ of the suspension was $6 \cdot 6-6 \cdot 8$. The incubation and measurement of the $\mathrm{O}_{2}$ uptake was carried out in conical Warburg vessels, which were placed in ice while they were prepared for the experiment. The main compartment contained $3 \mathrm{ml}$. of the tissue suspension, the side arm contained $1 \mathrm{ml}$. of the substrate solution including ATP, ${ }^{32} \mathrm{PO}_{4}$ and oxidizable substrates. All substrates were added as neutral sodium salts. The gas space contained $\mathrm{O}_{2}$.
When the manometers were ready for incubation the contents of side arm and main compartment were thoroughly mixed and the manometer was attached to the water bath kept at $20^{\circ}$. At intervals manometers were removed from the bath and the cups were transferred as rapidly as possible to a dish containing iced water. To stop further enzyme activity $0.5 \mathrm{ml} .30 \%$ trichloroacetic acid (TCA) (w/v) was added. The contents of the cup were then centrifuged for $15 \mathrm{~min}$. at $0^{\circ}$ and the supernatant was stored at $-14^{\circ}$ until it could be analysed. A number of duplicate sets without isotope were incubated at the same time in order to have sufficient material for the quantitative determination of non-isotopic substrates. In these cups $1 \mathrm{ml} .2 \mathrm{M}-\mathrm{HCl}$ was used to stop enzyme activity, because the yields of succinate and $\alpha$ ketoglutarate were slightly low in the presence of TCA.

Measurement of $\mathrm{O}_{2}$ uptake. As it was not possible, because of thermal equilibration, to measure manometrically the $\mathrm{O}_{2}$ uptake for the first few minutes, measurements were made on at least three parallel manometers incubated for longer periods and the average rates were used in the calculation. The rate of $\mathrm{O}_{2}$ uptake usually remained constant for at least $40 \mathrm{~min}$. and the subsequent fall was only slight. Hence extrapolation for the initial period was sufficiently accurate.

Separation of phosphate fractions. By the addition of suitable quantities of inorganic orthophosphate and ATP the experimental conditions were so arranged that these two phosphate fractions formed about $94 \%$ of all phosphates in the TCA filtrate. The remaining $6 \%$ came partly from the tissue, partly from impurities in the ATP preparations. Adenosine phosphates were separated from inorganic phosphate and other organic phosphates by the paperchromatographic methods of Hanes \& Isherwood (1949) and Eggleston \& Hems (1952).

Measurement of radioactivity. The beta counter tube (liquid type) of Veall (1948) was used. All the samples counted contained approximately $1.5 \mathrm{~N}-\mathrm{H}_{2} \mathrm{SO}_{4}$ (final concentration) as they were diluted after ashing without neutralization. Care was required to avoid adherence of ${ }^{32} \mathrm{PO}_{4}$ to the counter tube. This was found to occur when the radioactive solutions were neutral or alkaline. Two washings of the tube with $\mathrm{N}_{-} \mathrm{H}_{2} \mathrm{SO}_{4}$ followed by washings in water were found to remove any adherent ${ }^{32} \mathrm{PO}_{4}$, whereas washing with $\mathrm{KH}_{2} \mathrm{PO}_{4}$ or $\mathrm{K}_{2} \mathrm{HPO}_{4}$ was ineffective.

Calculation of labile adenosinepolyphosphate $\mathbf{P}$. The initial amounts of labile adenosinepolyphosphate $P$ were known from the analyses for ADP and ATP of the starting material. In incubated material only the sum of ATP and ADP was determined in most experiments, chromatography with the formic acid-isopropyl ether solvent being used. In general, only minor changes occurred in the sum of ATP and ADP during incubation, usually within the limits of error, but corrections were nevertheless introduced on the assumption that any decrease in the sum of ATP + ADP was solely due to a conversion of ATP into ADP. This assumption rests on 
the observation that the ultraviolet photographic technique of Markham \& Smith (1949) did not reveal at any time measurable amounts of AMP. The method would have shown quantities of AMP amounting to $3 \%$ (in terms of molecular equivalents) of those of ATP + ADP. The formation of AMP could therefore be neglected.

Differential determination of the specific activities of the two labile phosphate groups of ATP. The principle used was as follows. ATP was hydrolysed enzymically to ADP and inorganic phosphate and the two products were separated by paper chromatography. The specific activity of the ADP. phosphate was never found to be more than half the specific activity of inorganic phosphate, which means that under the test conditions only one phosphate of ADP reacted. Hence it was unnecessary to separate the phosphates of ADP, as all radioactivity found could be attributed to the terminal phosphate of ADP.

The TCA extract of the suspension $(1 \mathrm{ml}$.) was carefully neutralized with $2 \mathrm{~N}-\mathrm{NaOH}$ solution from a microburette, with a trace of phenol red as indicator. After buffering with $0.2 \mathrm{ml} .0 .1 \mathrm{M}$-triethanolamine buffer $(\mathrm{pH} \mathrm{7.4}) 0.1 \mathrm{ml}$. of the soluble ATP-ase preparation of Kielley \& Meyerhof (1948) was added and the volume was adjusted to $1.5 \mathrm{ml}$. The solution was incubated for $30 \mathrm{~min}$. at $38^{\circ}$, which proved sufficient for the complete hydrolysis of ATP. Chromatography was carried out according to Eggleston \& Hems (1952) on 15-25 $\mu$ l. samples.

Quantitative determination of substrates. As far as practicable the amounts of substrate removed and of end products formed were determined with incubated suspensions. The determinations were carried out, after centrifugation, in the supernatant of the $\mathrm{HCl}$-acidified suspensions. Deproteinization was unnecessary except in the determination of citric acid and of the sum of $\alpha$-ketoglutaric and succinic acids. Succinic acid was determined manometrically in the presence of succinic dehydrogenase (Krebs, 1937) without ether extraction, as interfering substances were not present. The sum of fumaric and malic acids was determined manometrically according to Nossal (1952) with washed suspensions of Lactobacillus arabinosus. Separate values for the two dicarboxylic acids were not required. $\alpha$-Ketoglutaric acid was determined manometrically according to Krebs (1951) and the sum of $\alpha$-ketoglutaric and succinic acid according to Krebs \& Eggleston (1945). Citric acid was determined according to Weil-Malherbe \& Bone (1949).

Control of substrate changes. Attempts were made to assess the contributions of individual oxidative reactions to the uptake of phosphate. It has not proved possible to separate quantitatively the individual enzyme systems without interfering with the phosphorylation mechanisms, but some degree of separation was achieved by the addition of intermediates in relatively high concentrations. When 0.01 or $0.02 \mathrm{M}$-succinate was added, the main substrate change was the conversion of succinate into fumarate and malate, the amounts of $\mathrm{O}_{2}$ used, succinate removed and fumarate plus malate formed being roughly in the proportions $1: 2: 2$ (see Table 2). When 0.01 or $0.02 \mathrm{M}$ - $\alpha$-ketoglutarate was the substrate, its conversion into fumarate and malate was the main, though by no means sole reaction. In Exp. 2, Table 3, for example, the amounts of $\mathrm{O}_{2}$ used, $\alpha$-ketoglutarate removed, and fumarate plus malate formed were in the proportion $1: 0 \cdot 78: 0 \cdot 64$, instead of $1: 1: 1$ expected for the quantitative reaction: $\alpha$-ketoglutarate $\rightarrow$ fumarate + malate. Malonate

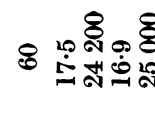

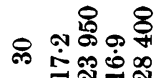

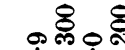

ㅇํํํํํ요

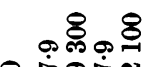

은 드음유

$\infty$ ب $\dot{\sim}=\dot{\infty}=$

요

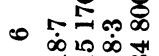

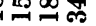

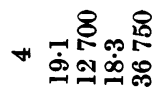

趈

$\infty$ $\dot{\infty}=\dot{\infty}$

N

+

車 $\infty \dot{\infty}$

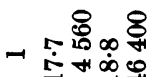

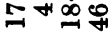

- $\begin{array}{r}\infty \\ \infty \\ \infty\end{array}$ 要
8

究审

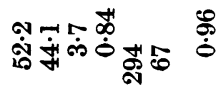

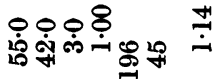

ஓ্ৰ.

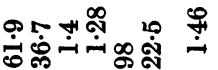

通

மீं

คึ

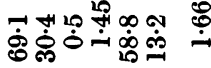

mo

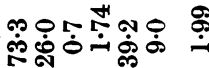

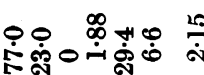

ஸ்.

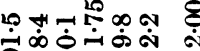

غ્ఠ,

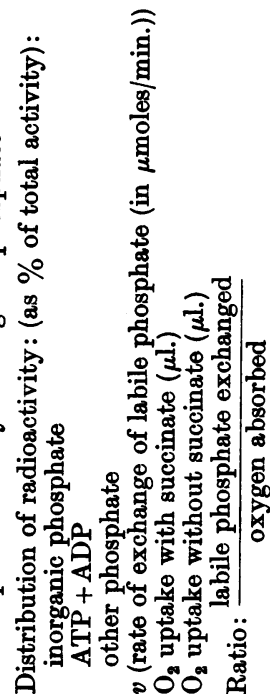


proved unsuitable for the separation of the step $\alpha$-ketoglutarate $\rightarrow$ succinate because ATP was not maintained in the presence of $0.002 \mathrm{M}$-malonate.

\section{RESULTS}

\section{Rate of incorporation of inorganic phosphate into ATP}

Succinate as substrate. Details of a representative experiment are given in Table 2. The amounts of ATP + ADP and of inorganic phosphate remained virtually constant throughout the $60 \mathrm{~min}$. period of incubation. Thus a steady state existed with regard to these two substances, as was postulated in the theoretical treatment. At the same time the specific activities of both substances underwent a change; inorganic phosphate gradually losing its activity and ATP becoming increasingly active. At the end of the incubation these two compounds still accounted for $94 \%$ of the total radioactivity in the system. It follows that no major side reactions of phosphate or ATP occurred. The rate of exchange of labile phosphate as calculated according to formula (1) gives reasonably consistent figures for the first four measurements but later the value fell.
The amounts of oxygen used, succinate removed, and fumarate and malate formed in this experiment are in the proportion $1: 1 \cdot 99: 1 \cdot 66$. Thus most of the oxygen consumption was due to the conversion of succinate into fumarate and malate. Summaries of three similar experiments on pigeon-breast muscle, rat liver and sheep heart are given in Table 3. These confirm, in general, the findings of the experiment recorded in Table 2. The best experiment, from the point of view of constancy of $v$ (equation 1 ) is Exp. 1 where pigeon-breast muscle served as the source of the phosphorylation system. Here the value for $v$ was maintained throughout the observation period. In all four experiments the initial phosphorylation quotients are somewhat above 2.

The specific activity of the labile ATP-phosphate approaches in most experiments a value equal to that of inorganic phosphate which indicates that both labile phosphate groups of ATP reacted under the test conditions.

Pigeon-breast muscle preparations oxidizing to fumarate and malate but incapable of oxidizing malate, obtained by washing minced tissue with water or isotonic saline, were found to have lost most of their phosphorylating capacity. ATP is not

\section{Table 3. Incorporation of ${ }^{32} \mathrm{PO}_{4}$ into ATP in tissue suspensions in the presence of succinate}

(Temp., $20^{\circ} ; 4 \mathrm{ml}$. suspension.)

Exp. 1: pigeon-breast muscle in 45 parts of medium; $0.02 \mathrm{M}$-succinate; $\mathrm{O}_{2}$ uptake, 5.33 $\mu \mathrm{l}$./min. with substrate, $1.83 \mu \mathrm{l}$./min. without substrate; average amount of labile phosphate of ATP per cup, $12 \cdot 0 \mu$ mole; of inorganic phosphate, 13.9 $\mu$ moles. Succinate removed after 30 min., $412 \mu l$.; fumarate + malate formed after 30 min., $299 \mu l$; ratio: succinate removed $/ \mathrm{O}_{2}$ used $=\mathbf{2 \cdot 5 7}$.

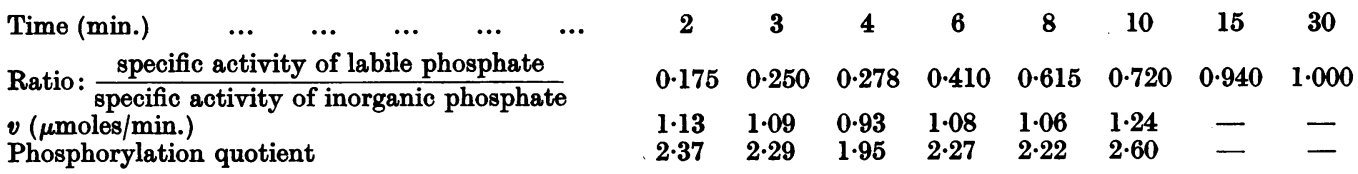

Exp. 2: rat-liver suspension in 30 parts of medium; 0.04 M-succinate; $\mathrm{O}_{2}$ uptake, 8.61 $\mu \mathrm{l}$. $/ \mathrm{min}$. with substrate for $30 \mathrm{~min}$., $517 \mu \mathrm{l} . / 60 \mathrm{~min}$.; $1.87 \mu \mathrm{l}$. $/ \mathrm{min}$. without substrate, $114 \mu \mathrm{l} . / 60 \mathrm{~min}$.; average amount of labile phosphate of ATP per cup, $18 \cdot 1 \mu$ moles; of inorganic phosphate, $17 \cdot 1 \mu$ moles. Succinate removed after 60 min., $895 \mu l$.; fumarate + malate formed, $847 \mu$ l.; ratio: succinate $\mathrm{removed} / \mathrm{O}_{2}$ used $=1 \cdot 73$.

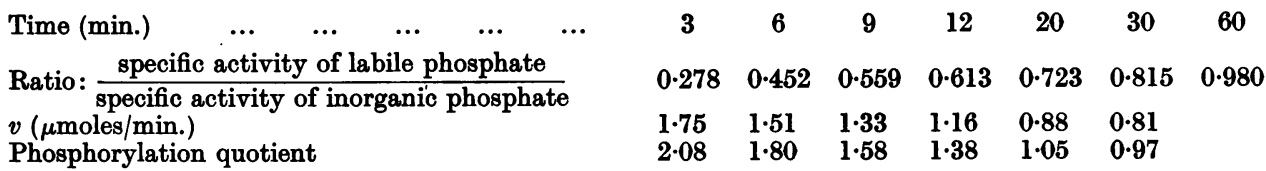

Exp. 3: sheep-heart muscle mince washed twice with 10 vol. 'stock saline' standing 5 min. at $0^{\circ}$ each time before filtration through muslin. Before use the mince was ground in a homogenizer and suspended in 15 parts of medium; $0.04 \mathrm{M}-$ succinate; $\mathrm{O}_{2}$ uptake, $5.95 \mu \mathrm{l}$./min. with substrate for $30 \mathrm{~min} ., 360 \mu \mathrm{l} . / 60 \mathrm{~min} . ; 3 \cdot 15 \mu \mathrm{l} . / \mathrm{min}$. without substrate, $139 \mu \mathrm{l} . /$ $60 \mathrm{~min}$; ; average amount of labile phosphate of ATP per cup, $18 \cdot 6 \mu$ moles; of inorganic phosphate, 20.0 $\mu$ moles. Succinate removed after $60 \mathrm{~min}$., $608 \mu \mathrm{l}$.; fumarate + malate formed after $60 \mathrm{~min}$., $598 \mu \mathrm{l}$.; ratio: succinate $\mathrm{removed} / \mathrm{O}_{2} \mathrm{used}=1 \cdot 69$.

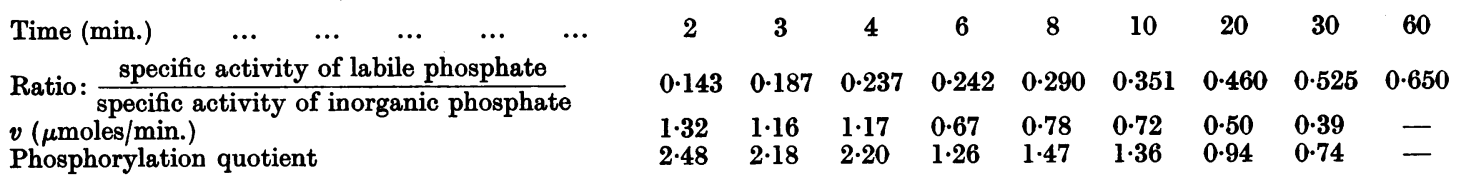


Table 4. Incorporation of ${ }^{32} \mathrm{PO}_{4}$ into $A T P$ in tissue suspensions in the presence of $\alpha$-ketoglutarate

(Temp., $20^{\circ}$; rat-liver suspensions in 30 parts of medium. $4 \mathrm{ml}$. suspension per cup.)

Exp. 1: $0.02 \mathrm{M}-\alpha$-ketoglutarate; $\mathrm{O}_{2}$ uptake with substrate, $4.9 \mu \mathrm{l} . / \mathrm{min}$. during first $45 \mathrm{~min} ., 245 \mu \mathrm{l} . / 60 \mathrm{~min}$.; without substrate, $175 \mu \mathrm{l} . / 60 \mathrm{~min}$; average amount of labile phosphate of ATP per cup, $13.7 \mu \mathrm{moles}$; of inorganic phosphate, $18 \cdot 8 \mu$ moles. After 60 min. $\alpha$-ketoglutarate removed, $195 \mu \mathrm{l}$.; succinate formed, $50 \mu \mathrm{l}$; fumarate + malate formed, $103 \mu \mathrm{l}$.

Ratio: $\frac{\text { specific activity of labile phosphate }}{\text { specific activity of inorganic phosphate }}$ $v$ ( $\mu$ moles/min.)

Phosphorylation quotient

$\begin{array}{lllllllll}0.184 & 0.271 & 0.354 & 0.460 & 0.543 & 0.653 & 0.939 & 1.000 & 1.000 \\ 1.49 & 1.36 & 1.26 & 1.25 & 1.20 & 1.26 & - & - & - \\ 3.41 & 3.11 & 2.88 & 2.86 & 2.74 & 2.88 & \text { (av. 3.01) } & -\end{array}$

Exp. 2: $0.01 \mathrm{M}-\alpha$-ketoglutarate; $\mathrm{O}_{2}$ uptake with substrate, $4.28 \mu \mathrm{l}$./min. during first $45 \mathrm{~min}$., $242 \mu \mathrm{l}$./60 min.; without substrate, $101 \mu \mathrm{l} . / 60 \mathrm{~min}$.; average amount of labile phosphate of ATP per cup, $13.5 \mu \mathrm{moles}$; of inorganic phosphate, $17.9 \mu$ moles. After $60 \mathrm{~min}$. $\alpha$-ketoglutarate removed, $189 \mu \mathrm{l}$; succinate formed, $\sim 0$; fumarate + malate formed, $155 \mu l$.

$\begin{array}{llllllllllllll}\text { Time (min.) } & \ldots & \ldots & \ldots & \ldots & \ldots & 3 & 6 & 9 & 12 & 20 & 30 & 60\end{array}$

Ratio: $\frac{\text { specific activity of labile phosphate }}{\text { specific activity of inorganic phosphate }}$ $v$ ( $\mu$ moles/min.)

Phosphorylation quotient

$\begin{array}{lllllll}0.222 & 0.418 & 0.523 & 0.653 & 0.854 & 0.925 & 1.000 \\ 1.14 & 1.18 & 1.38 & 1.11 & 1.30 & - & - \\ 2.98 & 3.09 & 3.61 & 2.91 & 3.40 & \text { (av. 3.20) } & \text { - }\end{array}$

Exp. 3: 0.01 M- $\alpha$-ketoglutarate; $\mathrm{O}_{2}$ uptake with substrate, $4.80 \mu \mathrm{l} . / \mathrm{min}$. during first $50 \mathrm{~min} ., 281 \mu \mathrm{l} . / 60 \mathrm{~min}$.; without substrate, $100 \mu \mathrm{l} . / 60$ min.; average amount of labile phosphate of ATP per cup, 16.2 $\mu$ moles; of inorganic phosphate, $18.0 \mu$ moles. After $60 \mathrm{~min}$. $\alpha$-ketoglutarate removed, $170 \mu \mathrm{l}$; succinate formed, $17 \mu \mathrm{l}$.; fumarate + malate formed, $119 \mu \mathrm{l}$.

Time (min.)

36

Ratio: $\frac{\text { specific activity of labile phosphate }}{\text { specific activity of inorganic phosphate }}$

$0.262 \quad 0.425$

9

12

20

30

60

$v(\mu$ moles $/ \mathrm{min}$.)

$1.54 \quad 1 \cdot 38$

Phosphorylation quotient

$\mathbf{3} \cdot 60 \quad \mathbf{3} \cdot 22$

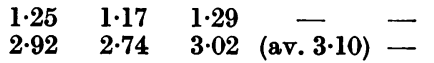

maintained in washed tissue suspensions and such preparations are therefore unsuitable for measurements of the phosphorylation quotient.

$\alpha$-Ketoglutarate as substrate. Three experiments on rat-liver suspension in which $\alpha$-ketoglutarate was the substrate are shown in Table 4. In general the results resemble those with succinate, but there is no major fall in the values for $v$ with time. The phosphorylation quotients are a little above 3 .

A major proportion of the $\alpha$-ketoglutarate removed was recovered as fumarate and malate and, except in Exp. 2, a smaller proportion as succinate. The data indicate that the greater part of the oxygen uptake was due to the oxidation of $\alpha$-ketoglutarate to a mixture of fumarate and malate. In Exp. 2 this reaction was responsible for approximately $80 \%$ of the oxidative processes.

Citrate as substrate. Fairly constant values for $v$ were found for the earlier stages of incubation, during which the phosphorylation quotient was in all experiments above 3 (Table 5). Accurate measurement of the substrate changes was not possible because the amounts of citrate removed were small in comparison with the total amount of citrate present. Some fumarate and malate as well as $\alpha$-ketoglutarate were found but these accounted for not more than $10 \%$ of the oxygen consumption. The main oxidative process in the presence of citrate was therefore probably the complete oxidation of citrate.

\section{Relative reactivity of the two labile phosphate groups}

A series of five experiments bearing on the problem of the relative reactivity of the two labile phosphate groups of ATP is given in Table 6. In Exp.1 the specific activities of the terminal and second phosphate groups were determined both separately and together. In the experiment on rat liver both labile phosphate groups exchanged at the same speed. In Exp. 2, pigeon-breast muscle and a commercial ATP preparation (Roche Products Ltd.) were used, a different result being obtained in that the second phosphate group reacted much more slowly than the first. After $10 \mathrm{~min}$. the terminal phosphate was already in equilibrium with inorganic phosphate whilst the specific activity of the second phosphate group was only one-quarter of that of inorganic phosphate.

In Exps. 3-5 only the combined specific activity of both phosphates was determined and in these cases a graph of the ratio specific activity of both labile phosphate groups/specific activity of inorganic phosphate against time gives information on the relative rates of reaction of the two labile phosphate groups. Smooth curves are obtained for Exps. 4 and 5 (as also for Exp. 1) indicating reactivity of both phosphate groups, but the plot of Exp. 3 (and that of Exp. 2) shows a discontinuity at a value of 0.5 for the above ratio. The concentration 
Table 5. Incorporation of ${ }^{32} \mathrm{PO}_{4}$ into ATP in tissue suspensions in the presence of citrate

(Temp., $20^{\circ}$; rat-liver suspension in 20 parts of medium. $4 \mathrm{ml}$. suspension per cup.)

Exp. 1 : $0.02 \mathrm{M}$-citrate; $\mathrm{O}_{2}$ uptake with substrate, 4.64 $\mu \mathrm{l}$./min., $278 \mu \mathrm{l}$. in $60 \mathrm{~min}$.; without substrate, $141 \mu \mathrm{l}$. in $60 \mathrm{~min}$; average amount of labile phosphate of ATP per cup, 16.9 $\mu$ moles; of inorganic phosphate, $16 \cdot 2 \mu$ moles.

\begin{tabular}{|c|c|c|c|c|c|c|c|c|c|}
\hline Time (min.) $\quad \ldots \quad \ldots \quad \ldots \quad \ldots$ & 2 & 3 & 4 & 6 & 8 & 10 & 20 & 30 & 60 \\
\hline Ratio: $\frac{\text { specific activity of labile phosphate }}{\text { specific activity of inorganic phosphate }}$ & $0 \cdot 193$ & $0 \cdot 264$ & $0 \cdot 332$ & $0 \cdot 430$ & 0.507 & 0.555 & 0.770 & 0.885 & $1 \cdot 000$ \\
\hline $\begin{array}{l}v \text { ( } \mu \text { moles/min.) } \\
\text { Phosphorylation quotient }\end{array}$ & $\begin{array}{l}1 \cdot 60 \\
3 \cdot 86\end{array}$ & $\begin{array}{l}1 \cdot 49 \\
3 \cdot 60\end{array}$ & $\begin{array}{l}1 \cdot 42 \\
3 \cdot 43\end{array}$ & $\begin{array}{l}1 \cdot 34 \\
3 \cdot 24\end{array}$ & $\begin{array}{l}1 \cdot 24 \\
3 \cdot 00\end{array}$ & $\begin{array}{l}1 \cdot 08 \\
2 \cdot 61\end{array}$ & $\begin{array}{l}0.935 \\
2 \cdot 26\end{array}$ & $\begin{array}{l}0 \cdot 975 \\
2 \cdot 36\end{array}$ & 二 \\
\hline
\end{tabular}

Exp. 2: 0.02 M-citrate and containing 1.0 ml. of $1: 1$ boiled pigeon-muscle extract; $\mathrm{O}_{2}$ uptake with substrate, 6.6 $\mu$ l./min. during first $30 \mathrm{~min}$.; $379 \mu \mathrm{l}$. in $60 \mathrm{~min}$.; without substrate, $333 \mu \mathrm{l}$. in $60 \mathrm{~min}$; average amount of labile phosphate of ATP per cup, 18.5 $\mu$ moles; of inorganic phosphate, $24 \cdot 4 \mu$ moles; fumarate + malate formed, $\sim 45 \mu l$.

Time (min.)

$\begin{array}{lllllllll}2 & 3 & 4 & 6 & 8 & 10 & 20 & 30 & 60\end{array}$

Ratio: $\frac{\text { specific activity of labile phosphate }}{\text { specific activity of inorganic phosphate }}$

$v$ ( $\mu$ moles/min.)

Phosphorylation quotient

$\begin{array}{lllllllll}0.168 & 0.234 & 0.312 & 0.455 & 0.508 & 0.571 & 0.726 & 0.906 & 1.000 \\ 1.97 & 1.95 & 1.94 & 2.02 & 1.80 & 1.73 & 1.75 & - & - \\ \mathbf{3} .43 & 3.30 & 3.29 & 3.42 & 3.05 & 2.93 & 2.97 & - & -\end{array}$

Exp. 3: $0.02 \mathrm{M}$-citrate; $\mathrm{O}_{2}$ uptake with substrate, 6.47 $\mu \mathrm{l}$./min., $388 \mu \mathrm{l}$. in $60 \mathrm{~min}$.; without substrate, $195 \mu \mathrm{l}$. in $60 \mathrm{~min}$.; average amount of labile phosphate of ATP per cup, 16.5 $\mu$ moles; of inorganic phosphate, 17.4 $\mu$ moles; $\alpha$-ketoglutarate + succinate formed, $\sim 48 \mu \mathrm{l}$; fumarate + malate formed, $\sim 50 \mu \mathrm{l}$. Citrate removed, $\sim 200 \mu \mathrm{l}$.

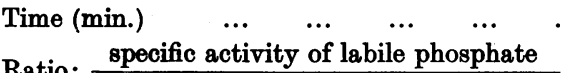

Ratio: $\frac{\text { specific activity of labile phosphate }}{\text { specific activity of inorganic phosphate }}$

$v$ ( $\mu$ moles/min.)

Phosphorylation quotient

$\begin{array}{ccccccccc}2 & 3 & 4 & 6 & 8 & 10 & 20 & 30 & 60 \\ 0.216 & 0.286 & 0.405 & 0.468 & 0.587 & 0.613 & 0.875 & 0.971 & 1.000 \\ 1.97 & 1.72 & 1.77 & 1.48 & 1.40 & 1.28 & 1.22 & - & - \\ 3.41 & 2.98 & 3.06 & 2.56 & 2.42 & 2.22 & 2.11 & - & -\end{array}$

\section{Table 6. Relative reactivity of the two labile phosphates groups of ATP}

(The total volume of fluid per cup was $4 \mathrm{ml}$. Unless stated otherwise the ATP preparation was that made according to LePage (1949). Pigeon-breast muscle extract was prepared by keeping freshly minced muscle with 1 part water for $10 \mathrm{~min}$. in a boiling-water bath and filtering at $20^{\circ}$. Other conditions as in previous experiments.)

Exp. 1. Rat-liver suspensions in 30 parts of medium. $0.02 \mathrm{M}$ - $\alpha$-ketoglutarate.

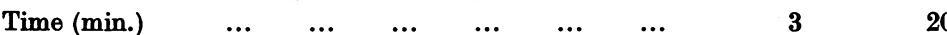

Ratio: $\frac{\text { specific activity of terminal phosphate of ATP }}{\text { specific activity of inorganic phosphate }} \quad \begin{array}{lllll}0.218 & 0.815 & 0.866 & 1.000\end{array}$

Ratio: $\frac{\text { specific activity of second phosphate of ATP }}{\text { specific activity of inorganic phosphate }}$

$\begin{array}{llll}0.208 & 0.806 & 0.870 & 1.000\end{array}$

Ratio: specific activity of both labile phosphate groups $\quad$\begin{tabular}{lllll}
\hline & 0.214 & 0.805 & 0.836 & 1.000
\end{tabular}

Exp. 2. Pigeon-breast muscle homogenates in 10 parts of medium. 0.04 M-succinate. ATP of Roche Products Ltd.

$\begin{array}{lllllll}\text { Time (min.) } \quad \ldots & \ldots & \ldots & \ldots & \ldots & \ldots\end{array}$

Ratio: $\frac{\text { specific activity of terminal phosphate of ATP }}{\text { specific activity of inorganic phosphate }}$

$\begin{array}{llll}5 & 10 & 20 & 40\end{array}$

60

Ratio: $\frac{\text { specific activity of second phosphate of ATP }}{\text { specific activity of inorganic phosphate }}$

0.550

$1 \cdot 0$

$1 \cdot 0$

$1 \cdot 0$

$1 \cdot 0$ specific activity of inorganic phosphate
Pigeon-breast muscle in 20 parts medium.

$0 \cdot 132$

$0 \cdot 244$

$0 \cdot 348$

$0 \cdot 432$

0.540

Exp. 3. Pigeon-breast muscle in 20 parts medium. 0.04 $\mathrm{m}$-succinate. $1 \mathrm{ml}$. boiled muscle extract.

Time (min.)

Ratio: $\frac{\text { specific activity of both labile phosphate groups }}{\text { specific activity of inorganic phosphate }}$

$$
5
$$

10

20

60

Exp. 4. Rat-liver suspensions in 20 parts of medium. $0.02 \mathrm{M}$-citrate. $1 \mathrm{ml}$. boiled pigeon-muscle extract.
Time (min.)
$\begin{array}{lllll}\ldots & \ldots & \ldots & \ldots & \ldots\end{array}$
3
20
30
60
$1 \cdot 000$

Ratio: $\frac{\text { specific activity of both labile phosphate groups }}{\text { specific activity of inorganic phosphate }}$

$0 \cdot 234$

0.726

0.906

Exp. 5. Pigeon-breast muscle suspension in 45 parts medium. 0.02 M-succinate.

Time (min.)

$\begin{array}{llllll} & \ldots & \ldots & \ldots & \ldots & \ldots\end{array} \quad \ldots$

410

15

Ratio: $\frac{\text { specific activity of both labile phosphate groups }}{\text { specific activity of inorganic phosphate }}$

$0 \cdot 278$

0.720

0.940

$1 \cdot 000$

Biochem. 1953, 54 
of the suspension was higher than usual in this experiment and the terminal phosphate was in equilibrium with inorganic phosphate in less than 5 min., whilst the second phosphate was not in equilibrium even after $60 \mathrm{~min}$.

These observations lead to the following conclusion: in both liver (Exps. 1 and 4) and pigeonmuscle (Exp. 5) suspensions two phosphate groups of ATP can react at equal rates, but under certain conditions the rate of reaction of the second phosphate may be slower than that of the first in the case of pigeon-breast muscle, e.g. when either boiled muscle extract (Exp. 3) or the ATP preparation of Roche Products Ltd., instead of the preparation according to LePage (Exp. 2), is present. Boiled muscle extract or Roche Products' ATP have no such effect on the reactivity of the second phosphate in liver suspensions.

The statement made by Krebs, Johnson, Eggleston \& Hems (1951) that only one phosphate of ATP reacts in muscle but two in liver is thus correct only under special conditions. The statement was based on experiments in which the ATP preparation of Roche Products Ltd. was used and is also correct when boiled muscle extract is present.

Boiled muscle extract was examined when it was found that the reactivity of the second phosphate in muscle suspension depended on the ATP preparation. It is evident from this finding that the slow reactivity of the second phosphate is due to an impurity accompanying ATP, and the fact that muscle extract produces the same effect indicates that it is an impurity derived from the tissue and not from the reagents introduced in the isolation of ATP. The nature of the impurity is so far obscure. The boiled extract contains an active myokinase which might be expected to increase the reactivity of the second phosphate rather than to reduce it.

\section{Anaerobic phosphorylation}

The quantitative significance of the phosphorylation quotients obtained in the preceding part of this paper depends on the absence of anaerobic phosphorylation under the test conditions. Whether this occurred was tested by repeating anaerobically some of the experiments recorded in Tables 3 and 4. There was a rapid decrease in the concentration of ATP in all anaerobic experiments (conditions as Exp. 2, Table 3, and Exp. 2, Table 4). In rat-liver suspension $35 \%$ of the original labile ATP phosphate was lost in $5 \mathrm{~min}$. at $20^{\circ}$. The remaining ATP contained small but measurable quantities of ${ }^{32} \mathrm{P}$, but the total count after $5 \mathrm{~min}$. was only $9 \%$ of the aerobic value in the presence of succinate and $13 \%$ in the presence of $\alpha$-ketoglutarate. As no steady state existed, the turnover rate could not be calcu- lated, but the conclusion may be drawn that such anaerobic phosphorylation as did occur was too slow to vitiate appreciably the calculations of the phosphorylation quotients.

\section{DISCUSSION}

Applicability of theory. A constancy of the $v$ values calculated from different pairs of $t$ and $x$ may be regarded as support, though not as proof, of the theory. Satisfactory constancy throughout the major part of the incubation period was obtained in experiments where $\alpha$-ketoglutarate was the substrate (Table 4) and also in Exp. 1 of Table 3 where succinate was the substrate and pigeon-breast muscle the source of enzyme. Thus the theory is satisfactorily obeyed under some conditions. Where deviations are observed, such as the fall of $v$ occurring in the later period of incubation (e.g. in some of the experiments with succinate or citrate), this is probably due to complicating factors not operating in the early part of incubation, or in the presence of $\alpha$-ketoglutarate. The fact that the phosphorylation quotients obtained are in essential agreement with the highest values found by other authors using entirely different methods gives further support to the theory.

Phosphorylation quotient for individual stages. In none of the experiments was the oxidative process strictly limited to a single stage, but when succinate was the substrate the major part of the oxidative reactions was the conversion of succinate into fumarate; not less than $80 \%$ of the oxygen uptake accounted for this reaction. In all experiments with succinate as substrate the phosphorylation quotient was near 2, generally a little above this value; a quotient of 2 for the reaction succinate $\rightarrow$ fumarate may therefore be taken as the best available value. Measurements with different methods by other authors (Cross, Taggart, Covo \&. Green, 1949; Eiler \& McEwan, 1949; Hunter \& Hixon, 1949 $a, b$; Copenhaver \& Lardy, 1952) have generally yielded somewhat lower phosphorylation quotients, the highest previously recorded values being $1 \cdot 7-1 \cdot 8$.

Phosphorylation quotients of the order of 3 were obtained when $\alpha$-ketoglutarate was the substrate and when the main reaction was the conversion of $\alpha$-ketoglutarate into a mixture of fumarate and malate (see Table 4). This reaction involves two stages and if the phosphorylation quotient is 2 for oxidation of succinate to fumarate and malate, and 3 for the conversion of $\alpha$-ketoglutarate into fumarate and malate, it must be 4 for the first step of the oxidation of $\alpha$-ketoglutarate, i.e. its conversion into succinate. This conclusion is in accordance with those of previous workers (Cross et al. 1949; Hunter \& Hixon, 1949a, $b$; Copenhaver \& Lardy, 1952; especially Hunter, 1951). 
The observations with citrate as substrate (Table 5) do not supply direct information on the phosphorylation quotient of individual stages as most of the citrate appeared to undergo complete oxidation. The figure of 3 observed supports other evidence showing that up to three phosphate molecules can react, on an average, per atom of oxygen consumed during the complete oxidation of intermediate metabolites (see authors quoted above and Judah, 1951; Lehninger \& Smith, 1949; Johnson \& Lardy, 1950).

Thermodynamic efficiency of oxidative phosphorylation. Estimates of the free-energy changes for the individual oxidative steps and for the hydrolysis of ATP holding for conditions similar to those prevailing in the experiments $\left(\mathrm{pH} 7 \cdot 0-7 \cdot 4 ; 0.2\right.$ atm. $\mathrm{O}_{2}$; 0.5 atm. $\mathrm{CO}_{2} ; 0.005 \mathrm{M}$-inorganic phosphate; ratio $\mathrm{ATP} / \mathrm{ADP}=10$ ) are given by Burton \& Krebs (1953). In the experiments reported in this paper the concentration of the organic substrates changes during the incubation, and, as any corrections taking into consideration substrate concentration are relatively small, no adjustments are made in the following calculation. According to Burton \& Krebs (1953) $\Delta G$ of the conversion of $\alpha$-ketoglutarate into succinate is $69.8 \mathrm{kcal}$. at equal concentrations of $\alpha$ ketoglutarate and succinate, and for the synthesis of ATP 14 kcal. Assuming a phosphorylation quotient of 4 the efficiency is therefore

$$
4 \times 14 \times 100 / 69.8=80 \% \text {. }
$$

Assuming a phosphorylation quotient of 2 for the conversion of succinate into fumarate the efficiency is $2 \times 14 \times 100 / 35 \cdot 7=78 \%$. In these calculations it is also assumed that the free energy of hydrolysis of ATP is not utilized for the synthesis of ATP under the test conditions, an assumption supported by the observation that the rate of anaerobic incorporation of ${ }^{32} \mathrm{PO}_{4}$ into ATP is very slow.

High efficiencies can be expected only if most of the respiration serves to resynthesize pyrophosphate bonds, which would imply that the rate of respiration is controlled by the rate at which the substrates for the synthesis of ATP become available. There is in fact evidence supporting this conception (Recknagel \& Potter, 1951; Kaplan, 1951; Lardy \& Wellman, 1952).

Phosphorylation coupled with the oxidation of cytochrome $c$. When succinate is oxidized by molecular $\mathrm{O}_{2}$ about one-third of the total free-energy change occurs in the reactions between cytochrome $c$ and succinate and two-thirds in the reactions between cytochrome $c$ and oxygen (Ball, 1944; Hunter, 1951). The free energy liberated between the stages lying in the interaction of cytochrome $c$ and succinate can thus at most account for the formation of one pyrophosphate bond. If two are formed, the free energy of the oxidation of cyto- chrome must also be utilized for the synthesis of pyrophosphate bonds, as already emphasized by Hunter (1951). An analogous calculation for the case of $\alpha$-ketoglutarate also suggests, although not as forcibly, that the free energy of the oxidation of cytochrome $c$ by oxygen is utilized.

Reactivity of the two phosphate groups of $A T P$. The data in Table 6 show that two phosphate groups of ATP are, under some conditions, equally labile, as judged by the rate of interchange with inorganic phosphate, whilst under others the terminal group reacts more rapidly than the second. Animal tissues are known to be able to phosphorylate ADP according to the reaction

$$
\mathbf{A D P}+\mathbf{P} \rightarrow \mathbf{A T P},
$$

and to possess the enzyme myokinase (Kalckar, 1943, 1951; Kotelnikova, 1948; Colowick, 1951), which converts $A D P$ reversibly into AMP and ATP,

$$
\mathrm{AMP}+\mathrm{ATP} \rightleftharpoons 2 \mathrm{ADP} \text {. }
$$

The balance of these two reactions (reaction 4 occurring twice) is the synthesis of ATP from AMP and $2 \mathrm{P}$. These two known reactions, together with action of ATP-ases, could account for the observations on the exchange of two labile phosphate groups reported in this paper (see also Novikoff, Hecht, Podber \& Ryan, 1952 ; Barkulis \& Lehninger, $1951 b$ ). Under conditions when both phosphate groups exchange at equal rates the myokinase reaction must be rapid in comparison to the synthesis of ATP by reaction (4). A low reactivity of the second phosphate group can be accounted for by the inhibition, or absence, of myokinase.

Whilst there is so far no evidence of a phosphorylation of AMP by a mechanism other than reaction (5), the possibility of a more direct reaction between AMP and inorganic phosphate cannot be ruled out.

\section{SUMMARY}

1. The rate of incorporation of $\left({ }^{32} \mathrm{P}\right)$ potassium dihydrogen phosphate $\left(\mathrm{KH}_{2}{ }^{32} \mathrm{PO}_{4}\right)$ into adenosinetriphosphate (ATP) in respiring tissue suspensions was measured under conditions where a steady state existed with respect to the concentrations of inorganic phosphate and ATP. From these measurements the rate at which the pyrophosphate bonds of ATP are formed was calculated. The theoretical and practical aspects of the procedure are discussed.

2. From the rate of formation of pyrophosphate bonds and of the simultaneous oxygen uptake the ratio equivalents of organic phosphate formed/ atoms of oxygen consumed, the 'phosphorylation quotient', was calculated. Its value was found to be near 2 when the main oxidative process was the oxidation by oxygen of succinate to fumarate and malate and near 3 when the main oxidative process 
was the oxidation of $\alpha$-ketoglutarate to fumarate and malate. The value of the ratio for the oxidation of ketoglutarate to succinate must therefore be 4 . These results confirm the highest values obtained by previous authors with entirely different procedures.

3. The thermodynamic efficiency of the oxidative phosphorylation was calculated to be of the order of $80 \%$ when succinate or ketoglutarate was the main substrate of oxidation. Efficiencies of this order are possible only if the free energy of the reactions between oxygen and the cytochromes is utilized.
4. In liver suspensions two phosphate groups of ATP reacted with almost identical speeds. In pigeon-breast muscle suspensions the reactivity of the second phosphate group was under some conditions much slower than that of the terminal group. The slow reactivity of the second phosphate group in muscle tissue appears to be due to the presence of a specific inhibitor of one of the enzymes concerned.

This work was aided by a grant from the Rockefeller Foundation.

\section{REFERENCES}

Bailey, K. (1949). Biochem. J. 45, 479.

Ball, E. G. (1944). Ann. N.Y. Acad. Sci. 45, 363.

Barkulis, S. S. \& Lehninger, A. L. (1951 a). J. biol. Chem. $190,339$.

Barkulis, S. S. \& Lehninger, A. L. (1951b). J. biol. Chem. 193, 597.

Belitzer, V. A. \& Tsibakowa, E. T. (1939). Biochemistry, Leningrad, 4, 516.

Burton, K. \& Krebs, H. A. (1953). Biochem. J. 54, 94.

Colowick, S. P. (1951). In Sumner, J. B. \& Myrbäck, K., The Enzymes, vol. 2, part I, p. 114. New York: Academic Press.

Colowick, S. P., Kalckar, H. M. \& Cori, C. F. (1941). J. biol. Chem. 137, 343.

Colowick, S. P., Welch, M. S. \& Cori, C. F. (1940). J. biol. Chem. 133, 359.

Copenhaver, J. H. jun. \& Lardy, H. A. (1952). J. biol. Chem. 195, 225.

Cross, R. J., Taggart, J. V., Covo, G. A. \& Green, D. E. (1949). J. biol. Chem. 177, 655.

Eggleston, L. V. \& Hems, R. (1952). Biochem. J. 52, 156. Eiler, J. J. \& McEwen, W. K. (1949). Arch. Biochem. 20, 163.

Engelhardt, W. A. (1930). Biochem. Z. 227, 16.

Engelhardt, W. A. (1932). Biochem. Z. 251, 343.

Green, D. E., Atchley, W. A., Nordmann, J. \& Teply, L. J. (1949). Arch. Biochem. 24, 359.

Hanes, C. S. \& Isherwood, F. A. (1949). Nature, Lond., 164, 1107.

Hummel, J. P. \& Lindberg, O. (1949). J. biol. Chem. 180, 1.

Hunter, F. E. jun. (1951). In McElroy, W. D. \& Glass, B., Phosphorus Metabolism, p. 297. Baltimore: The Johns Hopkins Press.

Hunter, F. E. jun. \& Hixon, W. S. (1949a). J. biol. Chem. $181,73$.

Hunter, F. E. jun. \& Hixon, W. S. (1949b). J. biol. Chem. $181,67$.

Johnson, R. B. \& Lardy, H. A. (1950). J. biol. Chem. 184, 235.

Judah, J. D. (1951). Biochem. J. 49, 271.

Judah, J. D. \& Williams-Ashman, H. G. (1951). Biochem. J. 48, 33.

Kalckar, H. M. (1939). Biochem. J. 33, 631.

Kalckar, H. M. (1941). Chem. Res. 28, 71.
Kalckar, H. M. (1943). J. biol. Chem. 148, 127.

Kalckar, H. M. (1944). Ann. N.Y. Acad. Sci. 45, 395.

Kalckar, H. M. (1951). In Sumner, J. B. \& Myrbäck, K., The Enzymes, vol. 2, part 1, p. 151. New York: Academic Press.

Kaplan, N. O. (1951). In Sumner, J. B. \& Myrbäck, K., The Enzymes, vol. 2, part I, p. 55. New York: Academic Press.

Kielley, W. W. \& Meyerhof, O. (1948). J. biol. Chem. 176, 591.

Kotelnikova, A. V. (1948). C.R. Acad.Sci. U.R.S.S. 59, 527.

Krebs, H. A. (1937). Biochem. J. 31, 2095.

Krebs, H. A. (1950). Biochim. biophys. Acta, 4, 249.

Krebs, H. A. (1951). Biochem. J. 47, 605.

Krebs, H. A. \& Eggleston, L. V. (1945). Biochem.J. 39, 408.

Krebs, H. A., Eggleston, L. V. \& Terner, C. (1951). Biochem. J. 48, 530.

Krebs, H. A., Johnson, M., Eggleston, L. V. \& Hems, R. (1951). Biochem. J. 49, xxxv.

Lardy, H. A. \& Wellman, H. (1952). J. biol. Chem. 195, 215.

Lehninger, A. L. \& Smith, S. W. (1949). J. biol. Chem. 181, 415.

LePage, G. A. (1949). Biochem. Prep. 1, 5. London: Chapman and Hall.

Markham, R. \& Smith, J. D. (1949). Biochem. J. 45, 294.

Nossal, P. M. (1952). Biochem. J. 50, 349.

Novikoff, A. B., Hecht, L., Podber, E. \& Ryan, J. (1952). J. biol. Chem. 194, 153.

Ochoa, S. (1941). J. biol. Chem. 138, 751.

Ochoa, S. (1943). J. biol. Chem. 151, 493.

Ochoa, S. (1947). Ann. N.Y. Acad. Sci. 47, 835.

Pardee, A. B. \& Potter, V. R. (1949). J.biol. Chem. 181, 739.

Potter, V. R. \& Elvehjem, C. A. (1936). J. biol. Chem. 114, 495.

Recknagel, R. O. \& Potter, V. R. (1951). J. biol. Chem. 191, 263.

Runnström, J., Lennerstrand, A. \& Borei, H. (1934). Biochem. Z. 271, 15.

Sheppard, C. W. (1948). J. appl. Phys. 19, 70.

Slater, E. C. (1950). Nature, Lond., 166, 982.

Veall, N. (1948). Brit. J. Radiol. 21, 347.

Weil-Malherbe, H. \& Bone, A. D. (1949). Biochem. J. 45, 377. 